\title{
Efektivitas Pembelajaran Matematika dengan Strategi Pembelajaran Aktif Index Card Match (ICM)
}

\author{
St. Syahdan"), Abdul Arif ${ }^{2)}$ \\ ${ }^{1,2}$ Universitas Kaltara \\ Email: stsyahdan89@gmail.com, arifabdul1476@gmail.com
}

\begin{abstract}
This research is an experimental research which aim to know whether the active learning strategy index card match is more effective than expository learning strategy used learning mathematic for students in class VII State Islamic Junior High School at Pitumpanua, Wajo Regency. The design of the research used Posttest Control Group Design. In this research therean experimental group namely VIID class with 32 students which was taught using ICM active learning strategies and one groupcontrolnamely VIIE class with the same number students taught by expository learning strategy. Technique collection data used result of the learning tests, observation sheets for student activity, and questionnaire sheets for the student respond. Data analyzed used description statistic analyzed and statistic inferential analyzed. According to description statistic analyzed obtained:1) In the experimental group, the result of the mathematics learningobtained average of 74,16 with the deviation standard of 12.972 in the high criteria, while in the group control the average learning result of student amount 66,12 with the deviation standard 12,973 in the medium criteria. 2) Learning activities of students in the experimental group showed a positive attitude with a percentage of $58.04 \%$ and $51.45 \%$ in the control group. 3) The Student responses in the experimental learning group showed a positive response with percentage of $89.87 \%$ while in the control group $63.73 \%$. Statistic inferential analyzed shows $t$ count $>t$ table (2.476> 1.67) with a significance of 5\%, So we can conclude that the hypothesis is accepted it mean that learning mathematics in grade VII students of State Islamic Junior High School at Pitumpanua country of Wajo Regency through ICM active learning strategies is more effective than expository learning strategies
\end{abstract}

Keyword: ICM (Index Card Match), Learning Result, Learning Activity

\begin{abstract}
ABSTRAK
Penelitian ini merupakan penelitian eksperimen dengan tujuan untuk mengetahui apakah strategi pembelajaran aktif Index Card Match (ICM) lebih efektif digunakan dalam pembelajaran matematika daripada strategi pembelajaan ekspositori pada siswa kelas VII MTs. Negeri Pitumpanua Kabupaten Wajo. Desain penelitian ini adalah Posttest Control Group Design. Penelitian ini terdapat satu kelompok eksperimen yaitu kelas VII $_{\mathrm{D}}$ dengan jumlah 32 siswa yang diajar dengan menggunakan strategi pembelajaran aktif ICM dan satu kelompok kontrol yaitu kelas $\mathrm{VII}_{\mathrm{E}}$ dengan jumlah siswa yang sama yang diajar dengan strategi pembelajaran ekspositori. Adapun teknik pengumpulan data dalam penelitian ini adalah tes untuk hasil belajar, lembar observasi untuk aktivitas siswa, dan lembar angket untuk respons siswa. Analisis data dilakukan dengan analisis statistika deskriptif dan analisis statistika inferensial. Berdasarkan analisis statistika deskriptif diperoleh: 1) Pada kelompok
\end{abstract}


eksperimen, untuk hasil belajar matematika siswa diperoleh rata-rata 74,16 dan standar deviasi 12,972 berada dalam kriteria tinggi, sementara pada kelompok kontrol diperoleh rata-rata hasl belajar siswa 66,12 dan standar deviasi 12,973 berada dalam kriteria sedang. 2) Aktivitas pembelajaran siswa pada kelompok eksperimen memperlihatkan sikap positif dengan persentase 58,04\% dan 51,45\% pada kelompok kontrol. 3) Respon siswa terhadap pembelajaran pada kelompok eksperimen menunjukkan respon yang positif dengan persentase $89,87 \%$ sedangkan pada kelompok kontrol sebesar 63,73\%. Analisis statistik inferensial menunjukkan $\mathrm{t}$ hitung $>\mathrm{t}$ tabel $(2,476>1,67)$ dengan signifikansi $5 \%$ sehingga disimpulkan bahwa hipotesis dapat diterima yang berarti pembelajaran matematika siswa kelas VII MTs. Negeri Pitumpanua Kabupaten Wajo dengan strategi pembelajaran aktif ICM lebih efektif dari strategi pembelajaran ekspositori.

Kata Kunci: Index Card Match (ICM), Hasil Belajar, Aktivitas Pembelajaran.

\section{PENDAHULUAN}

Pendidikan adalah salah satu wahana dalam mengembangkan serta meningkatkan kualitas sumber daya manusia. Salah satu masalah yang sering dihadapi dalam dunia pendidikan adalah lemahnya proses pembelajaran. Menurut Hamruni (2012:44) pembelajaran adalah proses mengatur lingkungan dalam menyampaikan materi pelajaran supaya siswa belajar. Sedangkan belajar merupakan proses perubahan tingkah laku sebagai hasil interaksi dengan lingkungannya dalam memenuhi kebutuhan hidupnya (Slameto, 2010: 2).

Dalam pembelajaran matematika di sekolah permasalahan yang palig sering muncul selama proses pembelajaran adalah biasanya hanya siswa dengan hasil belajarnya baik saja yang aktif dalam menjawab pertanyaan sementara yang kurang pandai tidak berani bertanya atau menjawab serta berusaha tidak terlibat dalam pembelajaran. Salah satu penyebab dari permasalahan ini adalah pemilihan strategi pembelajaran ekspositori oleh guru yang mana dalam prosesnya lebih menekankan kepada proses penyampaian materi secara lisan atau ceramah dari seorang guru kepada sekelompok siswa dengan maksud agar siswa dapat menguasai materi pelajaran secara optimal (Sanjaya, 2012:179). Hal ini akan menyulitkan siswa dalam mengembangkan kemampuan sosialisasinya. Selain itu, gaya komunikasi strategi ini lebih banyak terjadi satu arah sehingga menyebabkan pengetahuan siswa akan terbatas pada apa yang disampaikan guru. Keadaan pembelajaran yang kurang melibatkan interaksi sosial siswa seperti ini membuat siswa tidak dapat belajar secara mandiri, akibatnya siswa menjadi bosan dalam belajar yang berdampak pada rendahnya hasil belajar matematika siswa. 
Untuk itu, diperlukan suatu alternatif pembelajaran yang tepat dalam mengatasi permasalahan tersebut. Strategi pembelajaran yang mampu mengajak siswa untuk belajar secara aktif, yang berarti merekalah yang mendominasi aktivitas pembelajaran tidak hanya mental tapi juga melibatkan fisik. Menurut Gerlach dan Ely (Hamdani, 2011:19) apabila dihubungkan dengan proses belajar mengajar, "strategi adalah cara-cara yang dipilih untuk menyampaikan materi pelajaran dalam lingkungan pengajaran tertentu, yang meliputi sifat, lingkup, dan urutan kegiatan yang dapat memberikan pengalaman belajar kepada siswa”.

Strategi pembelajarn aktif yang dapat dijadikan solusi untuk mengatasi permasalahan di atas adalah strategi pembelajaran aktif Index Card Match (ICM)". Menurur Zaini, dkk. (2008:67) Index Card Match adalah sebuah strategi pembelajaran mencocokkan kartu soal dengan kartu jawaban, melalui interaksi dan kerjasama antarsiswa. Hal ini menunjukkan bahwa proses pembelajaran tidak hanya berupa penyajian informasi, dimana siswa datang lalu duduk dan hanya mendengarkan, tetapi mereka juga ikut berpartisipasi dalam proses pembelajaran. Strategi ini memuat unsur permainan sehingga siswa tidak akan bosan dalam belajar matematika. Tujuan penelitian ini adalah untuk mengetahui apakah Strategi Pembelajaran Aktif Index Card Match (ICM) lebih efektif digunakan dalam pembelajaran matematika daripada strategi pembelajaan ekspositori pada siswa kelas VII MTs. Negeri Pitumpanua Kabupaten Wajo. Adapun indikator keefektifan dalan penelitian ini yaitu ditinjau dari: ketuntasan belajar siswa, aktivitas siswa, dan respon positif siswa terhadap pembelajaran (Rahman, 2010:29).

\section{METODE PENELITIAN}

Penelitian ini adalah penelitian jenis eksperimen yang terdiri dari satu kelompok yang diajar dengan strategi pembelajaran aktif ICM (kelompok eksperimen) dengan jumlah 32 siswa dan satu kelompok yang diajar dengan strategi pembelajaran ekspositori (kelompok kontrol) dengan jumlah siswa yang sama.

\section{Desain Penelitian}

Desain dalam penelitian ini adalah Posttest Control Group Design. Berikut model desainnya: 
Tabel 1. Posttest Control Group Design.

\begin{tabular}{ccc}
\hline Group & perlakuan & posttest \\
\hline Eksperimen (E) & $\mathrm{T}_{1}$ & $\mathrm{O}$ \\
Kontrol (K) & $\mathrm{T}_{2}$ & $\mathrm{O}$
\end{tabular}

(Sumber: Tiro \& Ahmar, 2014: 27)

Keterangan :

$\mathrm{T}_{1}$ : Perlakuan pembelajaran untuk kelompok eksperimen dengan menggunakan strategi belajar aktif ICM

$\mathrm{T}_{2}$ : Perlakuan pembelajaran untuk kelompok kontrol dengan menggunakan strategi pembelajaran ekspositori

O : Tes akhir yang sama

\section{Populasi dan Sampel}

Populasi dapat didefinisikan sebagai keseluruhan aspek tertentu dari cirri, fenomena atau konsep yang menjadi pusat perhatian, sedangkan sampel adalah sejumlah anggota yang dipilih/ diambil dari suatu populasi (Tiro, 2008: 4). Populasi dari penelitian ini yaitu seluruh siswa kelas VII MTs Negeri Pitumpanua Kabupaten Wajo pada pada tahun ajaran 2012/ 2013. Random cluster sampling (sampel acak berkelompok) dilakukan untuk mengambil sampel dalam penelitian ini. Dari dua kelas yang telah dipilih dengan pertimbangan kelas homogen, satu kelas dijadikan kelompok eksperimen dan satu kelas sebagai kelompok kontrol.

\section{Pengumpulan Data}

Teknik pengumpulan data yang dilakukan adalah: data aktivitas guru dalam pembelajaran didapatkan melalui pengamatan dengan mengisi lembar observasi aktivitas guru oleh observator, data aktivitas siswa didapatkan berdasarkan pengamatan dengan mengisi lembar observasi sesuai kriteria aktivitas siswa dengan strategi belajar aktif ICM pada kelompok eksperimen dan kriteria aktivitas siswa dengan strategi pembelajaran ekspositori pada kelompok kontrol, data respon siswa dikumpulkan dengan menggunakan angket (kuesioner) yang diberikan pada akhir pembelajaran, sementara data hasil belajar siswa didapatkan melalui pemberian tes hasil belajar (posttest) secara langsung pada kedua kelompok sampel, 


\section{Teknik Analisis Data}

Analisis statistika deskriptif dimaksudkan untuk 1) Analisis data aktivitas guru dilakukan dengan menentukan persentase aktivitas yang dilakukan guru selama proses pembelajaran. Kriteria untuk menyatakan bahwa strategi pembelajaran aktif ICM efektif digunakan guru untuk mengelola pembelajaran, yaitu jika persentase penilaian $\geq 85 \%$ dari seluruh jumlah aspek yang diamati. 2) Analisis data aktivitas siswa dilakukan dengan menentukan frekuensi dan persentase aktivitas yang dilakukan siswa dalam pembelajaran. Kriteria untuk menyatakan bahwa aktivitas siswa berhasil ditingkatkan dalam penelitian ini yaitu apabila persentase siswa terlibat aktif dalam proses pembelajaran sedikitnya 50\% dari seluruh jumlah aspek yang diamati. 3) Analisis angket respon siswa dilakukan dengan analisis kualitatif. Kriteria untuk menyatakan bahwa strategi pembelajaran aktif ICM efektif memberikan respon positif siswa, yakni jika siswa yang memberikan respon positif $\geq$ $80 \%$ dari seluruh jumlah aspek yang direspon. 4) Anlisis hasil belajar siswa meliputi : nilai tertinggi, nilai terendah, nilai rata-rata, standar deviasi dan tabel distribusi frekuensi.

Analisis inferensial dilakukan agar peneliti dapat menguji hipotesis penelitian yang telah diajukan. Dalam analisis ini dilakukan: 1) Uji normalitas agar dapat diketahui bahwa data yang analisis berdistribusi normal atau tidak. Rumus yang digunakan adalah rumus chi-kuadra. Data berdistribusi normal bila $\chi_{\text {hitung }}^{2} \leq$ $\chi_{\text {tabel }}^{2}$ 2) Uji Homogenitas dilakukan agar dapat diketahui bahwa data yang dianalisis berasal dari varians yang sama. Data bersifat homogen jika $F_{\text {hitung }} \leq F_{\text {tabel }}$. 3) Pengujian Hipotesis dilakukan untuk menjawab hipotesis dengan kriteria pengujian adalah jika $t_{\text {hitung }}>t_{\text {tabel }}$ maka $\mathrm{H}_{1}$ diterima dam $\mathrm{H}_{\mathrm{o}}$ ditolak, dengan signifikan $\alpha=$ $5 \%$.

\section{HASIL DAN PEMBAHASAN}

\section{Hasil Penelitian}

Analisis deskripsi keterlaksanaan pembelajaran (hasil observasi aktivitas guru) menujukkan bahwa kemampuan guru dalam mengelola pembelajaran dengan menggunakan strategi pembelajaran aktif ICM pada kelompok eksperimen memiliki 
persentase sebesar $85,625 \%$ sedangkan pada kelompok kontrol sebesar 85,156\% dari seluruh jumlah aspek yang diamati.

Sementara, untuk aktivitas siswa dari aspek yang diamati pada kelompok eksperimen sebanyak 58,04\% siswa berperan aktif selama mengikuti pembelajaran, sedangkan pada kelompok kontrol sebanyak 51,45\%. Selanjutnya sebanyak $89,87 \%$ siswa kelompok eksperimen yang memberikan respon positif terhadap pembelajaran matematika, sementara siswa kelompok kontrol sebanyak 63,73\%.

Untuk hasil belajar matematika yang diperoleh melalui tes (posttest) dengan instrumen berupa soal essay yang sama diperoleh nilai rata-rata siswa pada kelompok eksperimen lebih tinggi yaitu 74,16, rentang nilai 52 dan standar deviasi 12,972 dibanding nilai rata-rata siswa pada kelompok kontrol yaitu 68,09, rentang nilai 52 dan standar deviasi 12,810

Analisis Inferensial menunjukkan setelah dilakukan perhitungan pada kelas eksperimen diperoleh nilai $\chi^{2}$ hitung $=\mathbf{6 , 7 5}$ dengan nilai $\chi^{2}$ tabel $=\mathbf{7 , 8 1} \mathrm{dk}=6-3=3$ dan taraf signifikansi $\alpha=0,05$, sementara pada kelas kontrol diperoleh nilai $\chi_{\text {hitung }}^{2}=4,06$ dengan nilai $\chi^{2}$ tabel $=7,81 \mathrm{dk}=\mathrm{k}-3=6-3=3$ dan signifikansi $\alpha=$ $5 \%$, sehingga dinyatakan bahwa data yang digunakan pada kedua kelompok berdistribusi normal karena $\chi^{2}$ hitung $<\chi^{2}$ tabel . Dari hasil perhitungan juga diperoleh harga $F_{\text {hitung }}=1,03$ dengan nilai harga $F_{\text {tabel }}=1,84$. Karena $F_{\text {hitung }}<F_{\text {tabel }}(1,03$ $<1,84)$, sehingga dinyatakan bahwa kedua kelompok tersebut adalah homogen.

Berdasarkan hasil pengujian hipotesis dengan menggunakan uji-t, diperoleh $t_{\text {hitung }}$ sebesar 1,883 dan $t_{\text {tabal }}$ sebesar 1,67 dengan $\alpha=0,05$. Berdasrkan analisis tersebut terlihat bahwa nilai $t_{\text {hitung }}>t_{\text {tabel }}(1,883>1,67)$. Dengan demikian dapat disimpulkan bahwa $\mathrm{H}_{\mathrm{o}}$ ditolak dan $\mathrm{H}_{1}$ diterima hal ini berarti rata-rata hasil belajar matematika pada kelompok eksperimen lebih baik dari kelompok kontrol.

\section{Pembahasan}

Strategi pembelajaran aktif index card match (ICM) diterapkan pada siswa kelas VII MTs. Negeri Pitumpanua Kabupaten Wajo sebagai suatu cara pembelajaran aktif yang menyenangkan untuk memahami suatu konsep atau topik pembelajaran melalui pemasangan kartu indeks (jawaban atau soal). Dalam penerapannya masing- 
masing siswa mendapatkan satu lembar kertas lalu diberi pemahaman bahwa mereka akan belajar sambil bermain secara berpasangan dimana sebagian dari mereka akan mendapat kartu soal dan sebagian lain akan mendapat kartu jawaban. Setelah itu, mereka diminta untuk berfikir dan menebak apa yang cocok untuk pasangan kartu mereka. Siswa kemudian diminta untuk mencari pasangan kartu mereka dengan mencocokkan kartu soal dengan kartu jawaban yang sesuai, melalui interaksi dan kerjasama. Selanjutnya kepada setiap pasangan secara bergantian membacakan soal dan menjelaskan jawaban yang diperoleh dengan suara keras agar didengar oleh teman-teman yang lain.

Ketuntasan belajar terlihat dari hasil belajr matematika siswa. Hasil belajar matematika pada kelompok eksperimen setelah diajar dengan strategi pembelajaran aktif index card match (ICM) berada pada kategori tinggi. Dari 32 siswa pada kelas ini $6,25 \%$ berada dalam kriteria sangat tinggi, 37,5 \% dalam kriteria tinggi, 28,125 $\%$ dalam kriteria sedang, $25 \%$ dalam kriteria rendah dan 3,125\% dalam kriteria sangat rendah dengan skor rata- rata 74,16 dari skor ideal yang mungkin dicapai 100 berada pada interval 45 - 97 dengan standar deviasi 12,972. Sedangkan pada kelompok kontrol, hasil belajar matematika siswa setelah diajar dengan penerapan Strategi Pembelajaran Ekspositori berada pada kategori sedang. Dari 32 siswa pada kelas ini terdapat $3,125 \%$ siswa yang memiliki hasil belajar matematika dalam kriteria sangat tinggi, 15,625\% dalam kriteria tinggi, 34,375 \% dalam kriteria sedang, 31,25\% dalam kriteria rendah dan 15,625\% dalam kriteria sangat rendah dengan skor rata- rata 66,12 dari skor ideal yang mungkin dicapai 100 berada pada interval 44- 96 dengan standar deviasi 12,973.

Berdasarkan Kriteria Ketuntasan Minimal yang digunakan di MTs. Negeri Pitumpanua Kabupaten Wajo, siswa dikatakan tuntas belajar jika hasil belajarnya telah mencapai $\geq 70$ dan ketuntasan klasikal jika $70 \%$ siswa telah mencapai skor $\geq$ 70. Hal ini dicapai oleh kelompok eksperimen, yang ditunjukkan dengan sebanyak 23 orang dengan persentase $71,88 \%$ siswa yang telah mencapai ketuntasan belajar, sedangkan pada kelomok kontrol sebanyak 14 orang dengan persentase 43,75\%. siswa yang telah mencapai ketuntasan belajar

Aktivitas siswa dalam pembelajaran menunjukkan bahwa aktivitas siswa yang diharap telah terpenuhi. Berdasarkan lembar observasi diketahui nilai rata-rata 
aktivitas siswa dalam pembelajaran sebesar 58,04\% pada kelompok eksperimen dan $51,45 \%$ pada kelompok kontrol. Hal ini sesuai dengan aktivitas yang diharapkan dengan penerapan Strategi Pembelajaran Aktif Index Card Match (ICM) pada kelompok eksperimen untuk mengatasi kebosanan siswa dengan memberikan kesempatan kepada siswa untuk terlibat aktif dalam pembelajaran matematika sehingga berdampak pada peningkatan hasil belajar matematika siswa. Adapun aktivitas guru dalam mengelola pembelajaran dikelompok eksperimen sebesar $85,625 \%$ dan kelompok kontrol sebesar 85,156 \% dari seluruh jumlah aspek yang diamati.

Respons setiap siswa terhadap pembelajaran melalui strategi pembelajaran aktif index card match (ICM) lebih positif dari pada respons siswa terhadap strategi pembelajaran ekspositori. Hal ini dapat dilihat dari hasil kuesioner yang diberikan kepada siswa menunjukkan 89,87\% siswa kelompok eksperimen memberikan respon positif terhadap pembelajaran, sementara sebanyak 63,73\% siswa kelompok kontrol yang memberikan respon positif.

Hasil analisis statistik inferensial menunjukkan bahwa terdapat perbedaan hasil belajar matematika siswa yang diajar menggunakan Strategi Pembelajaran Aktif Index Card Match dengan siswa yang diajar menggunakan Strategi Pembelajaran Ekspositori pada pokok bahasan himpunan. Hal ini ditunjukkan oleh rata-rata hasil belajar matematika untuk kelompok eksperimen $(74,16)$ lebih tinggi dari rata-rata hasil belajar untuk kelompok kontrol $(66,12)$, selain itu nilai $t_{\text {hitung }}>t_{\text {tabel }}$ yaitu 2,476 $>$ 1,67. Sehingga dapat disimpulkan bahwa pembelajaran matematika siswa kelas VII MTs. Negeri Pitumpanua Kabupaten Wajo melalui Strategi Pembelajaran Aktif Index Card Match lebih efektif daripada melalui Strategi Pembelajaran Ekspositori.

Dari hasil analisis data yang diperoleh, ternyata cukup mendukung teori yang telah dikemukakan pada kajian teori. Berdasarkan pengamatan peneliti pada saat eksperimen, ternyata keunggulan yang bisa diperoleh dengan menggunakan strategi pembelajaran aktif index card match di atas diantaranya adalah respon yang tinggi $(\geq$ 80\%) dimana siswa secara aktif terlibat penuh selama pembelajaran. Dalam penerapannya guru dapat lebih memaksimalkan kemampuan yang dimiliki dalam mengelola pembelajaran. Sedangkan ditinjau dari segi keaktifan, dalam proses 
pembelajaran kelas siswa yang diberikan Strategi Pembelajaran Aktif Index Card Match mempunyai kreaktivitas yang tinggi dan siswa bisa mengerjakan soal yang diberikan dengan rasa percaya diri karena sesuai dengan kemampuan masing-masing individual siswa.

\section{KESIMPULAN DAN SARAN}

Kesimpulan penelitian ini adalah pembelajaran matematika dengan menggunakan strategi pembelajaran aktif index card match (ICM) lebih efektif dilaksanakan pada siswa kelas VII MTs. Negeri Pitumpanua Kabupaten Wajo daripada strategi pembelajaran ekspositori dengan kriteria ketercapaian: (1) Hasil belajar matematika siswa kelas VIID MTs. Negeri Pitumpanua Kabupaten Wajo setelah penerapan Strategi Pembelajaran Aktif Index Card Match lebih dari 70 (nilai KKM) dan berada pada kategori tinggi dengan ketuntasan klasikal yakni $\geq 70 \%$ siswa telah mencapai nilai KKM dengan persentase $71,88 \%$ sedangkan pada kelas kontrol tidak mencapai ketuntasan klasikal, yakni kurang dari 70\% . 2) Rata-rata skor aktivitas siswa pada penerapan strategi pembelajaran aktif index card match (ICM) lebih tinggi daripada skor aktivitas siswa pada penerapan strategi pembelajaran ekspositori yakni berada pada kriteria aktif dengan persentase sebesar 58,04\%. 3) Respons siswa pada penerapan strategi pembelajaran aktif index card match (ICM) lebih tinggi dan berada pada kriteriai positif daripada respons siswa pada penerapan strategi pembelajaran ekspositori yakni sebesar $89,87 \%$.

Berdasarkan kesimpulan yang telah dikemukakan sebelumnya, adapun saran yang diajukan penulis adalah dalam pembelajaran matematika sebaiknya penerapan Strategi Pembelajaran Aktif Index Card Match dapat dijadikan sebagai salah satu alternatif untuk meningkatkan keaktifan siswa karena mampu mengatasi kebosanan siswa dalam belajar matematika sehingga akan meberikan dampak pada peningkatan hasil belajar matematika siswa.

\section{REFERENSI}

Hamdani. 2011. Strategi Belajar Mengajar. Bandung: Pustaka Setia.

Hamruni. 2012. Strategi Pembelajaran. Yogyakarta: Insan Madani. 
Sanjaya, Wina. 2006. Strategi Pembelajaran Berorientasi Standar Proses Pendidikan. Jakarta: Kencana.

Slameto. 2010. Belajar dan Faktor-Faktor yang Mempengaruhinya. Jakarta: Rineka Cipta.

Tiro, Muhammad Arif. 2008. Dasar-Dasar Statistika. Makassar: Andira Pulisher.

Tiro, M. A. \& Ahmar, A. S. 2014. Penelitian Eksperimen: Merancang, Melaksanakan, dan Melaporkan. Makassar: Andira Publisher.

Zaini, Hisyam, dkk.. 20008. Strategi Pembelajaran Aktif. Yogyakarta: Insan Madani.

Rahman, S. A. 2010. Penerapan Teorema Belajar Bruner dalam Pembelajaran Matematika. Tesis. Tidak diterbitkan. Makassar: PPs UNM. 